\title{
Scapular Winging Secondary to latrogenic Spinal Accessory Nerve Lesions
}

\author{
Selin Ozen, Sacide Nur Saracgil Cosar, Sevgi Ikbali Afsar and Sehri Ayas \\ Department of Physical Medicine and Rehabilitation, Baskent University Faculty of Medicine, Ankara, Turkey
}

\begin{abstract}
Motor innervation of trapezius and sternocleidomastoid (SCM) muscles is provided solely by the spinal accessory nerve (SAN). SAN palsy most often occurs as a result of iatrogenic injury to the nerve.

A patient, who had undergone neck dissection for thyroid cancer, presented with pain and reduced range of motion of the shoulders. Electroneuromyography revealed denervation of the trapezii and SCM muscles secondary to SAN injury. The patient was treated with a course of physical therapy (PT).

This case reminds us that a SAN lesion should be considered in the differential diagnosis of a patient presenting with shoulder pain following surgery of the neck. Even though unilateral SAN injury can eventually lead to atrophy of the trapezius, muscle asymmetry may not be obvious, especially in bilateral iatrogenic SAN injuries. In our experience, these patients benefit from PT. However, evidence to support the use of PT in the treatment of shoulder dysfunction secondary to SAN injury is insufficient; the optimum type and timing of PT requires further investigation. Development of best-practice guidelines in terms of management is necessary.
\end{abstract}

Key Words: Spinal accessory nerve, Electroneuromyography, Scapular winging.

How to cite this article: Ozen S, Cosar SNS, Afsar SI, Ayas S. Scapular Winging Secondary to latrogenic Spinal Accessory Nerve Lesions. J Coll Physicians Surg Pak 2021; 31(09):1111-1113.

\section{INTRODUCTION}

The spinal accessory nerve (SAN), or cranial nerve XI, provides motor innervation to the trapezius and sternocleidomastoid (SCM) muscles. The trapezius aids normal scapulothoracic movement by elevating, rotating and retracting the scapula. ${ }^{1} \mathrm{~A}$ lesion of the SAN results in denervation of the trapezius and winging of the scapula, causing shoulder pain and muscle weakness, which may in turn lead to secondary functional subacromial impingement. ${ }^{1}$

Rarely seen, the commonest cause of SAN injury is iatrogenic and mostly occurs during surgery involving the posterior triangle of the neck, such as cervical lymph node biopsy. ${ }^{2}$

As patients mostly present with complaints of shoulder pain, aSAN lesion may be overlooked and confused with diagnoses such as subacromial impingement and rotator cuff syndrome, thus delaying the correct diagnosis. ${ }^{3}$

Here, we present a case of bilateral shoulder pain and muscle weaknessfollowing thyroidectomy.

Correspondence to: Dr. Selin Ozen, Department of Physical Medicine and Rehabilitation, Baskent University Faculty of Medicine, Maresal Fevzi Cakmak Cad. 5. Sok. No: 48, Bahcelievler, Ankara, 06490. Turkey

E-mail: selinhassan@hotmail.com

Received: November 11, 2019; Revised: March 16, 2020;

Accepted: March 17, 2020

DOI: https://doi.org/10.29271/jcpsp.2021.09.1111

\section{CASE REPORT}

A 41-year male patient presented with bilateral shoulder pain and difficulty in raising his arms. Four weeks previously, he had undergone a thyroidectomy and regional lymph node dissection.

Examination of the musculoskeletal system revealed bilateral drooping of the shoulders with downwards rotation and protraction of the scapulae. Passive range of motion (ROM) of the shoulders was normal in all directions. Bilateral active shoulder abduction was reduced to 60 degrees and was accompanied by pain and winging of the scapulae. Neurological examination was normal. Radiographs of the cervical spine, chest and shoulders were normal. Electroneuromyography (ENMG) revealed bilateral partial severe lesions of the SANs: widespread denervation in the upper components of the trapezius muscles with reduced recruitment of the right trapezius and bilateral SCMs (Table I). Nerve conduction studies revealed low amplitude and prolonged latency of the SAN potentials bilaterally. The patient was diagnosed with bilateral partial SAN palsy with partial re-innervation of the right SCM. A rehabilitation programme of therapeutic electric stimulation to the trapezii, ROM and progressive resistance exercises (PRE) of the neck, shoulder girdle and postural training was commenced.

Two months later, both shoulders remained protracted. Active abduction of the right and left shoulders were pain-free and limited at 80 and 60 degrees, respectively. There was no motor weakness of the SCMs or the arms. 
Table I: Initial electroneuromyographic findings of the patient's right and left upper arm muscles showing denervation of the upper components of the trapezius bilaterally and partial reinnervation of the right sternocleidomastoid (SCM).

\begin{tabular}{|c|c|c|c|c|c|c|c|c|}
\hline \multirow{2}{*}{ EMG summary } & \multicolumn{4}{|c|}{ Spontaneous } & \multicolumn{3}{|c|}{ MUAP } & \multirow{2}{*}{$\begin{array}{l}\text { Recruitment } \\
\text { pattern }\end{array}$} \\
\hline & IA & Fib & PSW & Fasc & Amp & Dur & Poly & \\
\hline R.SCM & $\mathrm{N}$ & None & None & None & $\mathrm{N}$ & $\mathrm{N} \uparrow$ & $N \uparrow$ & Reduced \\
\hline R. Deltoid & $\mathrm{N}$ & None & None & None & $\mathrm{N}$ & $\mathrm{N}$ & $\mathrm{N}$ & $\mathrm{N}$ \\
\hline R.Trapezius (upper) & $\mathrm{N}$ & ++ & +++ & None & $\mathrm{N}$ & $\mathrm{N}$ & $\mathrm{N}$ & Reduced \\
\hline L. SCM & $\mathrm{N}$ & None & None & None & $\mathrm{N}$ & $\mathrm{N}$ & $\mathrm{N}$ & Reduced \\
\hline L. Deltoid & $\mathrm{N}$ & None & None & None & $\mathrm{N}$ & $\mathrm{N}$ & $\mathrm{N}$ & $\mathrm{N}$ \\
\hline L. Trapezius (upper) & $\mathrm{N}$ & +++ & ++++ & None & - & - & - & - \\
\hline R. \& L. Serratus anterior & $\mathrm{N}$ & None & None & None & $\mathrm{N}$ & $\mathrm{N}$ & $\mathrm{N}$ & $\mathrm{N}$ \\
\hline R. \& L. levator scapulae & $\mathrm{N}$ & None & None & None & $\mathrm{N}$ & $\mathrm{N}$ & $\mathrm{N}$ & $\mathrm{N}$ \\
\hline R. \& L. Rhomboid major & $\mathrm{N}$ & None & None & None & $\mathrm{N}$ & $\mathrm{N}$ & $\mathrm{N}$ & $\mathrm{N}$ \\
\hline
\end{tabular}

Table II: Post-treatment electromyographic findings of the patient's right and left upper arm muscles showing bilateral partial accessory nerve paralysis with partial reinnervation of the right trapezius muscle.

\begin{tabular}{|c|c|c|c|c|c|c|c|c|}
\hline \multirow{2}{*}{ EMG summary } & \multicolumn{4}{|c|}{ Spontaneous } & \multicolumn{3}{|c|}{ MUAP } & \multirow{2}{*}{$\begin{array}{l}\text { Recruitment } \\
\text { pattern }\end{array}$} \\
\hline & IA & Fib & PSW & Fasc & Amp & Dur. & Poly & \\
\hline R. SCM & $\mathrm{N}$ & None & None & None & $\mathrm{N}$ & $N \uparrow$ & $\mathrm{N} \uparrow$ & Reduced \\
\hline R. Deltoid & $\mathrm{N}$ & None & None & None & $\mathrm{N}$ & $\mathrm{N}$ & $\mathrm{N}$ & $\mathrm{N}$ \\
\hline R.Trapezius (upper) & $\mathrm{N}$ & None & + & None & $\mathrm{N}$ & $\mathrm{N}$ & $\mathrm{N} \uparrow$ & Reduced \\
\hline R. Infraspinatus & $\mathrm{N}$ & None & None & None & $\mathrm{N}$ & $\mathrm{N}$ & $\mathrm{N}$ & $\mathrm{N}$ \\
\hline L. SCM & $\mathrm{N}$ & None & None & None & $\mathrm{N}$ & $\mathrm{N} \uparrow$ & $\mathrm{N} \uparrow$ & Reduced \\
\hline L. Deltoid & $\mathrm{N}$ & None & None & None & $\mathrm{N}$ & $\mathrm{N}$ & $\mathrm{N}$ & $\mathrm{N}$ \\
\hline L. Trapezius (upper) & $\mathrm{N}$ & None & ++ & None & $\mathrm{N}$ & $\mathrm{N}$ & $\mathrm{N} \uparrow$ & Reduced \\
\hline L. Infraspinatus & $\mathrm{N}$ & None & None & None & $\mathrm{N}$ & $\mathrm{N}$ & $\mathrm{N}$ & $\mathrm{N}$ \\
\hline R. \& L. Serratus anterior & $\mathrm{N}$ & None & None & None & $\mathrm{N}$ & $\mathrm{N}$ & $\mathrm{N}$ & $\mathrm{N}$ \\
\hline R. \& L. levator scapulae & $\mathrm{N}$ & None & None & None & $\mathrm{N}$ & $\mathrm{N}$ & $\mathrm{N}$ & $\mathrm{N}$ \\
\hline R. \& L. Rhomboid major & $\mathrm{N}$ & None & None & None & $\mathrm{N}$ & $\mathrm{N}$ & $\mathrm{N}$ & $\mathrm{N}$ \\
\hline
\end{tabular}

Follow-up ENMG findings were consistent with bilateral partial SAN paralysis with partial re-innervation of the trapezii (Table II).

\section{DISCUSSION}

The SAN is a motor nerve which originates from the C1-C4 spinal segments. The SAN supplies motor innervation to the SCM and then innervates the trapezius via the posterior triangle of the neck. Therefore, injury of the distal segment of the SAN in the posterior triangle results in denervation of the trapezius. However, a proximal lesion resulting in denervation of both the SCM and trapezius, as seen in this case, is uncommon.

This case reminds us to include iatrogenic SAN palsy, secondary to surgery of the posterior triangle of the neck in the differential diagnosis of winging of the scapulae. Even when the SAN remains intact, demyelination or devascularisation of the nerve may still occur during surgery. Other than lymph node biopsy, cases of SAN palsy due to tumours of the jugular foramen, excision of small tumours and radical neck dissection have been reported. ${ }^{2,4}$
Here, PT resulted in reduction in pain and some increase in ROM. Effectiveness of PT following SAN injury remains inconclusive; the use of orthotics for scapula support, ${ }^{5}$ electrotherapy ${ }^{6}$ and soft tissue therapy, ${ }^{7}$ have been suggested. Gleno-humeral joint ROM is maintained using cervical spine and shoulder exercises. Maintaining shoulder mobility reduces the risk of occurrence of secondary pathologies, such as adhesive capsulitis. ${ }^{8}$ PRE overloads the muscle, thus overcoming disuse atrophy and enhancing neural adaptation. ${ }^{9}$

A SAN lesion should be considered in the differential diagnosis of a patient presenting with shoulder pain, especially following neck surgery, as accompanying signs such as weakness of shoulder abduction and forward elevation appear much later. ${ }^{2,10}$ Eventually, a SAN injury can lead to atrophy of the trapezius. However, muscle asymmetry may not be obvious, especially in bilateral iatrogenic SAN injuries. In our experience, these patients benefit from PT. However, the optimum type and timing of PT requires further investigation. Development of best-practice guidelines in terms of management is necessary. 


\section{CONFLICT OF INTEREST:}

The authors declared no conflict of interest.

\section{PATIENT'S CONSENT:}

The consent of the patient, on which this case was based, was taken prior to the writing of the manuscript.

\section{AUTHORS' CONTRIBUTION:}

SIA, SA: Acquisition, analysis, or interpretation of data.

SO, SNSC: Substantial contributions to the conception or design of the work.

SO, SNSC, SIA, SA: Drafting the work or revising it critically for important intellectual content.

SO, SNSC, SIA, SA: Final approval of the version to be published.

SO, SNSC, SIA, SA: Agreement to be accountable for all aspects of the work in ensuring that questions related to the accuracy or integrity of any part of the work are appropriately investigated and resolve.

\section{REFERENCES}

1. Sergides SS, Nikolopoulos DD, Polyzois IG. Idiopathic spinal accessory nerve palsy. A case report. Orthopaedics Traumatology Surg Res 2010; 96(5):589-92. doi: 10.1016/ j.otsr.2010.03.017

2. Williams WW, Twyman RS, Donell ST, Birch R. The posterior triangle and the painful shoulder: Spinal accessory nerve injury. Ann R Coll Surg Engl 1996; 78(6): 521-5.
3. Nakamichi KI, Tachibana S. Iatrogenic injury of the spinal accessory nerve: Results of repair. J Bone Joint Surg Am 1998; 80(11):1616-21. doi: 10.2106/00004623-199811 000-00007.

4. Lee S, Yang S, Lee J, Kim I. Spinal accessory neuropathy associated with the tumour located on the jugular foramen. Ann Rehabil Med 2013; 37(1):133-7. doi: 10.5535/arm. 2013.37.1.133.

5. Kizilay A, Kalcioglu MT, Saydam L, Ersoy Y. A new shoulder orthosis for paralysis of the trapezius muscle after radical neck dissection: A preliminary report. Eur Arch Otorhinolaryngol 2006; 263(5):477-80. doi: 10.1007/ s00405-005-1017-z.

6. Akgun K, Aktas I, Uluc K. Conservative treatment for late-diagnosed spinal accessory nerve injury. Am J Phys Med Rehabil 2008; 87(12):1015-21. doi: 10.1097/PHM.0b013e $31818 \mathrm{e} 6019$.

7. Shimada $Y$, Chida S, Matsunaga T, Sato M, Hatakeyama K, Itoi E. Clinical results of rehabilitation for accessory nerve palsy after radical neck dissection. Acta Otolaryngol 2007; 127(5):491-97. doi: 10.1080/00016480600895151.

8. Patten C, Hillel A. The 11th nerve syndrome. Accessory nerve palsy or adhesive capsulitis? Arch Otolaryngol Head Neck Surg 1993; 119(2):215-20. doi: 10.1001/arc hotol.1993.01880140105016.

9. Kolt G, Snyder-Mackler L. Physical therapies in sport and exercise. ed. 2nd, New York: Churchill Livingstone; 2007.

10. Kuhn JE, Plancher KD, Hawkins RJ. Scapular winging. J Am Acad Orthop Surg 1995; 3:319-25. 